\title{
Las costas, regiones de desarrollo del turismo
}

\section{Editorial}

\author{
Carlos Gauna Ruíz de León* Rosa Maria Chávez Dagostino** \\ Universidad de Guadalajara (México)
}

\begin{abstract}
Resumen: Las costas se han convertido en espacios predilectos para la realización de actividades turísticas, y esto ha provocado modificaciones en el medio natural generando afectaciones insostenibles en espacios marítimos y terrestres en los destinos, para satisfacer a una demanda creciente de visitantes, que cada vez requieren nuevos satisfactores, por lo que las actividades deben ser reguladas para su uso adecuado. Esta dinámica ha generado un incremento de nuevos pobladores atraídos por los beneficios laborales o por segunda residencia, un nuevo tipo de turísmo que hace de los lugares de playa su "casa" temporalmente. Las poblaciones locales reciben los beneficios de la actividad turística como empleo, la ampliación de servicios públicos y la generación de riqueza, pero también los efectos negativos como el deterioro ambiental general, la pérdida de identidad, cultura y tradiciones, además de sus espacios sociales, que deben compartirse con los turistas. Por ello, las comunidades locales buscan la preservación cultural de sus fiestas populares, entre otros. Presentamos en este volumen, trabajos que analizan la configuación del turismo en espacios costeros, cómo se construyen a partir de las iniciativas públicas, privadas y cooperativas. También acerca de la construcción de su identidad turística a partir de las imágenes representativas, el papel de la ciencia y de la planeación sostenible basada en la percepción de los turistas y los habitantes locales sobre las capacidades económicas y socioculturales. Estos permiten hacer una aproximación a la realidad de las zonas costeras a partir del turismo, los retos a los que se enfrentan en la planificación y operación, las condiciones de vida de las poblaciones locales y del medio ambiente natural, pero también las oportunidades que ofrece el turismo para el desarrollo y bienestar de la población cuando se realizan procesos sustentables.
\end{abstract}

Palabras Clave: Cultura; Impactos; Turismo Sustentable; Planificación y Comunidades Locales.

\section{Coasts, tourism development regions}

Abstract: The coasts have become favorite spaces for tourist activities, this has caused modifications in the natural environment generating unsustainable damages in maritime and terrestrial spaces in the destinations, to satisfy an increasing demand of visitors, who increasingly require new satisfiers. Therefore, the activities must be regulated for their proper use. This dynamic has generated an increase in new residents attracted by employment benefits or by second residence, a new type of tourism that makes beach places their "home" temporarily. Local people receive unfair benefits of tourism such as employment, expanding public services, and the generation of wealth, but also the negative effects as general environmental degradation, loss of identity and traditions, as well as their social spaces, which must be shared with tourists. For this reason, local communities seek the cultural preservation of their popular festivals, among others. We present in this volume, work that analyze the configuration of tourism in coastal spaces, how the public, private and cooperative initiatives are built. Also, about the construction of their tourist identity from representative images, the role of science and sustainable planning based on tourists and local inhabitants' perception of economic and socio-cultural capacities. These allow an approximation to the reality of coastal areas based on tourism, the challenges they face in planning and operation, the living conditions of local populations and the natural environment, but also the opportunities it offers for the development and well-being of the local population when sustainable processes are carried out.

Keywords: Culture; Impacts; Sustainable Tourism; Planning; Local Communities.

* Universidad de Guadalajara (México); E-mail: carlosg@cuc.udg.mx; https://orcid.org/0000-0002-8325-9397

** Universidad de Guadalajara (México); E-mail: rosac@cuc.udg.mx ; https://orcid.org/0000-0001-9063-2957 
Las costas, superficie terrestre sujeta a cambios de salinidad que ocupan los ecosistemas costeros e incluye lagunas, playas, dunas, manglares y humedales entre otros, constituyen paisajes sumamente diversos resultantes de una gran heterogeneidad geomorfológica, climática, ecológica y socioeconómica.

No existe una definición única para "costa", lo que dificulta delimitarla. Algunos autores han tratado de establecer su extensión, refiriéndose a la costa como la parte terrestre más influenciada por la proximidad al mar y la parte del océano más afectada por el continente (Hinrichsen, 1998), no obstante, esta influencia puede darse a varios kilómetros de distancia de la línea de costa. Los diversos servicios que proveen estos ecosistemas no han sido cuantificados en términos absolutos, pero se consideran invaluables para la humanidad y la vida misma en la Tierra. Al ser espacios de una gran diversidad biológica y fuerte atractivo sociocultural y económico, tradicionalmente han sido utilizados en actividades productivas agrícolas, pesqueras y de servicios en el último siglo, muy asociados al turismo que ha generado múltiples sinergias empresariales, pero también hibridaciones culturales, efectos sobre el territorio y conflictos de competencia por y uso de los recursos (Hjalager, 2020).

Las costas proveen características únicas que son de gran atractivo para los turistas, principalmente relacionado con el sol, la arena y el mar, donde además suceden diversos fenómenos socioculturales que vinculan las costas con el continente adentro. Sin embargo, existen problemas asociados al crecimiento económico, al cambio de uso del suelo y a la apropiación del territorio de diversas formas, lo que ha traído destrucción del ambiente, exclusión y pobreza. Existe la necesidad de enfoques más holísticos que permitan el crecimiento económico a partir del turismo costero y al mismo tiempo mantener la sustentabilidad (Ghosh, 2011).

La preservación del entorno natural y de la riqueza cultural allí asentadas son consideradas una prioridad por derecho propio, pero también una fuente indispensable para el sostenimiento responsable de la actividad turística como vía de desarrollo para las poblaciones humanas implicadas. Si el conjunto de factores que degradan estas regiones en el mundo, son principalmente de origen antropogénico (Nichols, Zinnert, \& Young, 2019), a lo que el turismo contribuye activamente, entonces esta actividad tiene una gran responsabilidad en la conservación del patrimonio natural y cultural asociado a estas regiones costeras.

El debate del desarrollo sostenible, en su más amplia acepción, sintetizado en los "Objetivos del Desarrollo Sostenible" propuestos por la ONU, ha llevado a las diversas disciplinas que intervienen, a buscar explicaciones y soluciones a los problemas y retos que se tienen en las regiones (ONU, 2015).

Es por ello que se han reunido esfuerzos para la presentación de un número especial de "Pasos Revista de Turismo y Patrimonio Cultural", que aborda diferentes tratamientos teóricos y casos de estudio sobre el turismo en las regiones costeras. Se incluyen diversas aproximaciones a su realidad, a su patrimonio y a su problemática, que enfocan el debate sobre el potencial socioeconómico a partir del turismo, así como acciones posibles para reconducir sus efectos no deseados y la presentación de propuestas viables de uso responsable (el ejercicio de acción de la responsabilidad inmediata de cada uno de los actores del sistema turístico).

El objetivo de este número especial es pues, presentar trabajos que, desde diversos enfoques, proponen como espacio de su investigación las zonas costeras, para lo cual se incluyen trabajos de México, España, Chile, Honduras y Ecuador. Esto permite conocer las diversas condiciones en la que se desarrolla el turismo, con aportaciones de mejora en sus prácticas, las condiciones en las que se relacionan las poblaciones locales y la interelación con el entorno terrestre y marítimo.

Los mamíferos marinos se han adoptado como parte del patrimonio turístico natural en prácticamente todo el mundo. Guillermo Villalba y Maria Vanesa Sánchez Crow presentan la importancia que tiene la conservación de la vida silvestre propia de las costas como son los delfines Tursiops truncatus y, como la zona es aprovechada para su avistamiento en una reserva de la vida silvestre, en Puerto El Morro (Ecuador). Esta actividad se ha convertido en una fuente de ingresos para diversas empresas. El trabajo de los autores se centró en caracterizar los recorridos que ofertan las empresas para conocer las condiciones de trabajo y el apego a las normativas implementadas por la autoridad, así como la percepción de los visitantes. Ambas acciones permitieron construir una guía de campo para el avistamiento que permita reforzar mecanismos de protección del entorno en general.

En la comunidad de José María Morelos, localizada en el municipio de Tomatlán en la costa de Jalisco, México, Emma Lizeth Noriega Garza y Stella M. Arnaiz Burne, estudiaron los impactos asociados al turismo donde describen las condiciones en las que viven las comunidades locales bajo el influjo del desarrollo turístico. Presentan un comparativo de la percepción local en los años 2009 y 2019, sobre diversas problemáticas sociales y de la implementación del turismo en la región, lo que permite explicar las condiciones de vida que no ha mejorado y, que ahora se enfrentan a una nueva realidad, donde 
los efectos negativos agravan su ya precaria condición de vida. Este trabajo tiene una pertinencia sobresaliente, ya que en esa zona se proyecta de un megadesarrollo turísitico, él cual es en la fase de obtener los permisos de construcción. Este incluye un aeropuerto que está en operación. Este proyecto se asocia a otros que desde hace más de cuarenta años se han desarrollado en la región, asociados a áreas naturales protegidas, que están en una zona de alta fragilidad ambiental.

La preocupación por el uso de los espacios naturales que proveen de servicios ecosistémicos por la actividad turística, se expresa en el trabajo que presentan Abigail Rosales Flores y Elizabeth Olmos Martínez, acerca de la Laguna de Coyuca, Guerrero, en México. El trabajo presenta una encuesta aplicada a los turistas para conocer sus motivaciones de viaje, la percepción que tienen sobre los atractivos de la zona, la importancia que tienen los servicios ecosistémicos que generan las lagunas costeras y su disposición a pagar un precio adicional por el uso de esos recursos, a fin de que se canalicen para proteger el patrimonio y realizar mejores adecuaciones para el uso turístico.

Sergi Yanes Torrado, presenta un recorrido histórico y bibliográfico de las investigaciones que se han desarrollado en el importante destino del mediterráneo español, la Costa Brava. El trabajo hace énfasis en los tópicos más abordados y las ausencias que se destacan. Constituye un referente histórico de la construcción del destino turístico, la importancia de los procesos normativos gubernamentales y el interés de los actores locales y externos, que provocaran el crecimiento económico de la región, de forma particular, a partir del turismo. Va más allá de la revisión de documentos científicos, pues rescata proyectos, planes y de forma marginal obras de literatura que suceden en la región, otorgando voz a los hechos que suceden en la construcción de un espacio urbano, los conflictos y las desavenencias en las reuniones públicas donde se debate el futuro de la región, el trabajo es un espacio donde se presentan las principales aportaciones en la construcción del destino, a juicio del autor, permite entender de una forma amplia las condiciones de un debate permanente, que va desde la función pública a la descripción académica. Es, por tanto, un aporte que sintetiza una dinámica social de una de las regiones que mayor presencia de turismo tiene en España y en el mundo.

Un trabajo novedoso que presenta a la ciencia como recurso para el desarrollo turístico sostenible de los Archipiélagos Patagónicos en Chile, es el de Fabien Pierre Marie Bourlon que "revela" un recurso territorial mediante la selección y puesta en valor de objetos científicos, en colaboración con distintos actores. Esto plantea el desafío de transformar el objeto ciencia, en un recurso territorial especifico, para su desarrollo socioeconómico. El proceso de "apropiación" de los recursos para la creación de un destino sustentable se realiza a través de la selección, la justificación, la conservación, la exposición y la valorización. Es así como en los Archipiélagos Patagónicos la oferta elaborada en base a recursos científicos apropiados por los actores locales, crea un destino sustentable. El autor busca comprender este proceso de valorización de conocimientos científicos como objeto patrimonial para el turismo con la finalidad de un desarrollo apropiado por una comunidad local.

Los destinos insulares se asocian a las costas, donde en ocasiones el formato del turismo que se desarrolla no es el masivo. Thania Vanessa Ramos Zúniga, Rosa María Chávez Dagostino y Liliane Cristine Schlemer Alcântara, analizan el turismo comunitario en Honduras que es incipiente, donde algunas localidades garífunas en la costa caribeña han incursionado en el turismo como una fuente alternativa de ingresos a la pesca artesanal, donde la captura ha disminuido notablemente en los últimos años. Su objetivo fue analizar los emprendimientos turísticos de base comunitaria en los poblados de East End y Chachahuate.

Las costas en el mundo se encuentran cada vez más afectadas por los asentamientos humanos. La expansión urbana conlleva un importante cambio en los usos del suelo, especialmente sobre el litoral (Barragán \& de Andrés, 2016; Ramírez Barragán, Rivera Herrera, \& Ledezma Elizondo, 2014), hecho que se exacerba en los destinos turísticos como Puerto Vallarta en México. María de los Ángeles Huízar Sánchez, Jorge Luis López Ramos y José Alfonso Baños Francia analizan la modernización voraz urbana de Puerto Vallarta, en la costa de Jalisco, México, con la colaboración de autoridades y promotores inmobiliarios. El objetivo de su trabajo es analizar el proceso de turistificación que enfrenta la ciudad, producto del desarrollo inmobiliario que impulsa la transformación de la vivienda y el comercio en favor del turista.

Por otra parte, los fenómenos religiosos en las costas frecuentemente están asociados a características naturales de la región que matizan las características culturales y se sincretizan volviéndose de interés para los destinos turísticos. En este sentido Blanca Viridiana Aguirre Tejeda, Ana María Salazar Peralta y César Gilabert presentan las festividades patronales en la región de la costa occidental del Pacífico medio en México, como parte del patrimonio cultural inmaterial que favorece la cohesión social, la identidad colectiva, la paz y la conciencia ecológica y son susceptibles de patrimonialización. 
$\mathrm{Su}$ objetivo es contribuir al conocimiento de la riqueza patrimonial de los pueblos costeros que han quedado sujetos al turismo.

Otro tema que se incluyó en este volumen fue la complejidad de la imagen de los destinos de costa a partir del estudio de Menorca en España, donde Alfons Xavier Méndez Vidal hace aportaciones metodológicas y estudia tanto el contenido de las imágenes como su significado para analizar su función en la configuración de la imagen turística. La imagen de los destinos turísticos constituye una línea de investigación de atención creciente, debido a que su papel central en la elección del lugar al cual se desplazan los turistas. Los autores muestran a los destinos de costa como un producto complejo donde más allá del concepto de sol y playa, emerge un importante aspecto paisajístico que incluye los núcleos de población.

Los destinos turísticos aceleran la transformación de las costas, por lo que éstos elaboran iniciativas de diferente índole en el mundo, para una actividad turística sostenible que debería regirse por una planificación integrada basada en objetivos no solamente económicos, si no también socio-culturales y ambientales, así como la toma de decisiones transparente y participativa. Elizabeth Olmos-Martínez, Juan Pedro Ibarra-Michel y Mónica Velarde-Valdez, evalúan el desempeño de la actividad turística rumbo a la sostenibilidad en Loreto, Baja California Sur, México a través de la percepción de los turistas y actores clave.

\section{Bibliografía}

Barragán, J. M. y De Andrés, M. 2016. Expansión urbana en las áreas litorales de América Latina y Caribe. Revista de Geografia Norte Grande, (64), 129-149. https://doi.org/10.4067/s0718-34022016000200009

Ghosh, T. 2011. Coastal Tourism: Opportunity and Sustainability. Journal of Sustainable Development, 4(6), 67-71. https://doi.org/10.5539/jsd.v4n6p67

Hinrichsen, D. 1998. Coastal waters of the world: Trends, Threats and Staregies. Washington, DC: Island Press.

Hjalager, A. M. 2020. Land-use conflicts in coastal tourism and the quest for governance innovations. Land Use Policy, 94(March 2019), 104566. https://doi.org/10.1016/j.landusepol.2020.104566

Nichols, C. R., Zinnert, J. y Young, D. R. 2019. Degradation of Coastal Ecosystems: Causes, Impacts and Mitigation Efforts. In L. D. Wright y C. R. Nichols (Eds.), Tomorrow's Coasts: Complex and Impermanent (p. 374). Springer International Publishing. https://doi.org/10.1007/978-3-319-75453-6

ONU. 2015. ODS. Retrieved from https://www.un.org/sustainabledevelopment/es/objetivos-de-desarrollo-sostenible/

Ramírez Barragán, L. A., Rivera Herrera, N. L. y Ledezma Elizondo, M. T. 2014. Crecimiento demográfico y marginación urbana en Bahía de Banderas, Nayarit . Cuadernos de Arquitectura y Asuntos Urbanos, 59-80. 